HORTSCIENCE 27(5):434-436. 1992.

\title{
Evaluation of Melon Germplasm for Resistance to Downy Mildew
}

\author{
Claude E. Thomas ${ }^{1}$ and E.L. Jourdain ${ }^{2}$ \\ U.S. Department of Agriculture, Agricultural Research Service, U.S. \\ Vegetable Laboratory, Charleston, SC 29414
}

Additional index words. Cucumis melo, Pseudoperonospora cubensis, disease resistance, foliar disease

\begin{abstract}
Field evaluations for resistance against downy mildew, incited by Pseudoperonospora cubensis [(Berk. and Cart.) Rostow], were conducted on 942 U.S. Plant Introductions (PI) of Cucumis melo L. (melon). A disease index (DI) was calculated for each entry. Based on DI, PI 124112 was highly resistant $(D I=3.7)$, and PIs 124111 , 122847, 124210, 145594, and 165525 were resistant $(D I=3.0,2.8,2.6,2.7$, and 2.5, respectively). PIs 124111 and 124112 had one or more plants that exhibited a highly resistant reaction type (RT 4). Resistant (RT 3) plants were identified in 31 accessions, and 49 accessions bad moderately resistant (RT 2) plants.
\end{abstract}

Downy mildew of melon and other cucurbits is incited by Pseudoperonospora cubensis. The disease has a wide geographic distribution (Palti, 1975) and causes severe losses in melon production near the Atlantic Seaboard and Gulf of Mexico in the United States (Whitaker and Davis, 1962). The principal methods of disease control are the use of protective fungicides and host resistance (Chupp and Sherf, 1960). Environ-

\footnotetext{
Received for publication 12 July 1991. Accepted for publication 13 Jan. 1992. Mention of a trade name or a proprietary product does not constitute a guarantee or warranty of the product by the U.S. Dept. of Agriculture, and does not imply approval of it to the exclusion of other products that also may be suitable. The cost of publishing this paper was defrayed in part by the payment of page charges. Under postal regulations, this paper therefore must be hereby marked advertisement solely to indicate this fact. ${ }^{1}$ Research Plant Pathologist.

${ }^{2}$ Horticulturist.
}

mental, economic, and energy conservation concerns are placing increasing emphasis on the need for development of commercially acceptable, resistant cultivars (Thomas, 1982). The U.S. Plant Introduction collection is a possible source of resistant germplasm against this disease.

The purpose of this study was to evaluate available melon Plant Introductions (PIs) from the U.S. Plant Introduction collection for resistance to a local isolate of $P$. cubensis pathotype 4 , the incitant of downy mildew. Because pathotypes $1,2,3,4$, and 5 of $P$. cubensis are highly compatible with at least one Cucumis melo differential genotype and pathotype 4 is highly compatible with all differential genotypes (Thomas et al., 1987), evaluations against pathotype 4 should provide a valid indication of potential resistance against it and the other four pathotypes. This report gives the results of the evaluation of 942 C. melo (melon) PIs and four control cultivars. 
Table 1. Disease indices of melon U.S. Plant Introductions (PI) that had one or more plants with a reaction type $\mathrm{e}^{\mathbf{z}}(\mathrm{RT}) \geq 2$ and cultivars to artificial inoculation with Pseudoperonospora cubensis in glasshouse/dew chamber replicated trials.

\begin{tabular}{|c|c|c|c|c|c|}
\hline PI/Cv. & $\begin{array}{c}\text { Disease } \\
\text { index }^{y}\end{array}$ & $\mathrm{PI} / \mathrm{Cv}$. & $\begin{array}{c}\text { Disease } \\
\text { index }\end{array}$ & PI/Cv. & $\begin{array}{l}\text { Disease } \\
\text { index }\end{array}$ \\
\hline PI 116666 & 1.8 & PI 126145 & 1.1 & PI 171594 & 1.2 \\
\hline PI 116667 & 1.2 & PI 136224 & 1.4 & PI 174133 & 1.2 \\
\hline PI 122847 & 2.8 & PI 145594 & 2.7 & PI 176930 & 1.2 \\
\hline PI 123188 & 1.5 & PI 157071 & 1.8 & PI 177334 & 1.0 \\
\hline PI 123493 & 1.8 & PI 157081 & 1.6 & PI 179666 & 1.3 \\
\hline PI 123494 & 1.4 & PI 161375 & 1.8 & PI 179669 & 1.0 \\
\hline PI 123498 & 1.4 & PI 163206 & 1.7 & PI 179677 & 1.1 \\
\hline PI 123500 & 1.5 & PI 163219 & 1.1 & PI 179895 & 1.1 \\
\hline PI 123502 & 1.6 & PI 164320 & 1.0 & PI 180280 & 1.0 \\
\hline PI 123683 & 1.6 & PI 164323 & 1.6 & PI 180283 & 1.2 \\
\hline PI 123684 & 1.8 & PI 164329 & 1.1 & PI 180428 & 1.6 \\
\hline PI 123689 & 1.5 & PI 164330 & 1.5 & PI 182952 & 1.0 \\
\hline PI 123823 & 1.7 & PI 164331 & 2.1 & PI 183037 & 1.2 \\
\hline PI 123824 & 1.5 & PI 164343 & 1.9 & PI 183055 & 1.2 \\
\hline PI 124092 & 1.4 & PI 164418 & 1.3 & PI 183311 & 1.8 \\
\hline PI 124102 & 1.3 & PI 164492 & 1.4 & PI 192939 & 1.2 \\
\hline PI 124103 & 1.6 & PI 164493 & 2.0 & PI 193495 & 1.1 \\
\hline PI 124109 & 1.6 & PI 164551 & 2.2 & PI 200816 & 1.1 \\
\hline PI 124111 & $3.0^{x}$ & PI 164610 & 1.2 & PI 208741 & 1.4 \\
\hline PI 124112 & 3.7 & PI 164635 & 1.2 & PI 211956 & 1.2 \\
\hline PI 124206 & 1.7 & PI 164653 & 1.2 & PI 212803 & 1.6 \\
\hline PI 124208 & 1.6 & PI 164723 & 1.3 & PI 212895 & 1.4 \\
\hline PI 124210 & 2.6 & PI 164756 & 1.2 & Controls & \\
\hline PI 124214 & 1.6 & PI 164794 & 1.6 & MR-1 & 4.0 \\
\hline PI 124436 & 1.4 & PI 164797 & 1.5 & Seminole & 3.0 \\
\hline PI 124552 & 1.8 & PI 164815 & 1.4 & Cinco & 2.0 \\
\hline PI 125875 & 1.8 & PI 165450 & 1.0 & Ananas & \\
\hline PI 125901 & 1.3 & PI 165513 & 1.6 & Yokneam & 1.0 \\
\hline PI 126030 & 1.0 & PI 165525 & 2.5 & & \\
\hline PI 126090 & 2.2 & PI 169348 & 1.0 & & \\
\hline
\end{tabular}

${ }^{2}$ Leaves one and two on glasshouse-produced plants at the two-expanded leaf stage were inoculated with $5.0 \times 10^{3}$ sporangia/ml from a local isolate of $P$. cubensis. Inoculated plants were incubated in a dew chamber for $18 \mathrm{~h}$ at $20 \mathrm{C}$ and were then placed in the glasshouse for 5 days. On the 6 th day after inoculation, plants were returned to the $20 \mathrm{C}$ dew chamber for $18 \mathrm{~h}$ and ratings for downy mildew reaction type (RT) were made at 7 days postinoculation. Reaction type descriptors are as follows: RT $1=10$ - to $15-\mathrm{mm}$ irregular, chlorotic lesions with abundant sporulation that may extend beyond the apparent margins of the lesions. RT $2=$ Type " 1 " lesions, above, mixed with type " 3 " lesions, below. RT $3=3$ - to 4-mm irregular to circular chlorotic lesions with water-soaked margins beneath and sparse sporulation. RT $4=1 \mathrm{~mm}$, circular, chlorotic lesions with necrotic centers and watersoaked margins beneath and extremely limited or no readily apparent sporulation.

'Weighted disease indices were calculated from the RTs to give the following rating scale: RT $1=$ susceptible. RT $2=$ moderately resistant. RT $3=$ resistant. RT $4=$ highly resistant. LSD $(P=0.05)$ $= \pm 0.5$.

xNot available from U.S. Plant Introduction Station.

Preliminary field studies were made in nonreplicated plots to evaluate PI accessions for downy mildew-resistant plants. Plots were composed of two to five plants, depending on availability and viability of seeds. Inoculum was prepared from a local isolate of $P$. cubensis maintained on cotyledons of melon 'Ananas Yokneam'. Cotyledons that supported abundant sporulation by the pathogen were collected and shaken vigorously in distilled water to dislodge the sporangia. The resulting sporangial suspension was filtered through a layer of cheesecloth, and the concentration was determined with the aid of a hemacytometer and adjusted to $2.0 \times 10^{4}$ sporangia/ml. The adaxial leaf surfaces were sprayed with this inoculum using a Micro Ulva (Micron Sprayers Ltd., Bromyard, U.K.) when the plants were at the 10-leaf stage. Two, and sometimes three, inoculations were necessary to ensure adequate disease development if dewfall did not occur following inoculation. In all cases, inocula were prepared and administered as described each of the Corn-Packs trays were cut in half to produce two sets of six cells each, for a total of four replicates per entry. These packs of six cells were completely randomized to form the four replicates. Seedlings were grown in a glasshouse to the two-expanded leaf stage.

Inoculum was produced as described above for the field tests, with the exception that the concentration was adjusted to $5.0 \times 10^{3}$ sporangia $/ \mathrm{ml}$. The adaxial surfaces of all leaves of all test and control plants were sprayed with this inoculum to incipient runoff using a Paasche Type $\mathrm{H}$ airbrush (Paasche Airbrush, Chicago) at $27.5 \mathrm{kPa}$. After inoculation, plants were placed in a dark 20C dew chamber for $18 \mathrm{~h}$, then kept on a glasshouse bench for 5 days. Six days postinoculation, plants were returned to the dew chamber for $18 \mathrm{~h}$ to enhance sporulation. Classifications for RT were made on the 7th day postinoculation.

Leaves one and two of each plant were observed with the aid of a stereo microscope at magnifications up to $\times 60$ to determine RT. These RT ratings were used to calculate a weighted disease index (DI) for each entry using Williams' (1985) formula. Based on these DIs, entries were assigned to the following resistance classes: $1=$ susceptible, $2=$ moderately resistant, $3=$ resistant, and $4=$ highly resistant .

In the replicated glasshouse trials, 82 PIs contained resistant plants (Table 1). Based on DI for these 82 PIs, PI 124112 was highly resistant $[(\mathrm{DI}=3.7), \operatorname{LSD}(P=0.05)=$ \pm 0.5 ] with $75 \%$ of the plants exhibiting RT 4. PI 124111 was rated resistant (DI = 3.0), with $33 \%$ of the plants having RT 4 and $44 \%$ having RT 3. The most resistant control, breeding line MR-1 (DI = 4.0), was derived from 90319, an inbred line of PI 124111 (Thomas, 1986). PIs 122847, 124210, 145594 , and 165525 were resistant (DI = $2.8,2.6,2.7$, and 2.5 , respectively), with $100 \%, 100 \%, 100 \%$, and $90 \%$ of the plants having a $\mathrm{RT} \geq 2$. Of the remaining 76 PIs, 27 had plants that were rated resistant (RT $=3$ ), and 49 PIs had one or more plants that were rated moderately resistant $(\mathrm{RT}=$ 2). Even though some PIs contained primarily susceptible plants, the few RT 3 plants in some of these PIs may represent useful sources of resistance. Only PI 124112 had a DI significantly higher (3.7) than that of the most resistant cultivar, Seminole (DI = 3.0). The origin of downy mildew resistance in 'Seminole' is uncertain. It was released in 1960 as a selection from open-pollinated fruit, with 'Smith's Perfect' and a Hale type included in the pedigree (Whitner, 1960). Eight additional PIs, 126030, 164320, 165450, 169348, 177334, 179669, 180280, and 182952, had one plant each with RT $=2$, but their DIs were rated susceptible (1.0).

Although no PIs were identified that had an overall DI higher than that of the most resistant melon line, MR-1, the identification of highly resistant plants within the PIs tested (Table 1) offers additional sources for the development of downy mildew-resistant melon cultivars. 


\section{Literature Cited}

Chupp, C. and A.F. Sherf. 1960. Vegetable diseases and their control. Ronald Press, New York. p. 299-302.

Palti, J. 1975. Pseudoperonospora cubensis. CMI descriptions of pathogenic fungi and bacteria. no. 457, Commonwealth Mycol. Inst., Kew, U.K.

Thomas, C.E. 1982. Resistance to downy mildew in Cucmis melo plant introductions and American cultivars. Plant Dis. 66:500-502.

Thomas, C.E. 1986. Downy and powdery mildew resistant muskmelon breeding line MR-1. HortScience 21:329.

Thomas, C.E., T. Inaba, and Y. Cohen. 1987. Physiological specialization in Pseudoperonospora cubensis. Phytopathology 77:1621-1624. Whitaker, T.W. and G.N. Davis. 1962. Cucur- bits: Botany, cultivation, and utilization. Interscience, New York. p. 168-169.

Whitner, Jr., B.F. 1960. Seminole. A high-yielding, good quality, downy and powdery mildewresistant cantaloupe. Univ. of Florida Agr. Expt. Sta., Gainesville, Fla. Circular S-122.

Williams, P.H. 1985. Crucifer genetics cooperative resource book. Univ. of Wisconsin, Madison. p. D3. 